Document downloaded from:

http://hdl.handle.net/10251/95242

This paper must be cited as:

De Rosario Martínez, H.; Page Del Pozo, AF.; Mata Amela, V.; Besa Gonzálvez, AJ.; Moreno Cano, R. (2012). PROPAGATION OF ARTIFACT ERRORS ON KINEMATIC VARIABLES. EFFECT ON EULER ANGLES. Journal of Biomechanics. 45:293-293. doi:10.1016/S0021-9290(12)70294-4

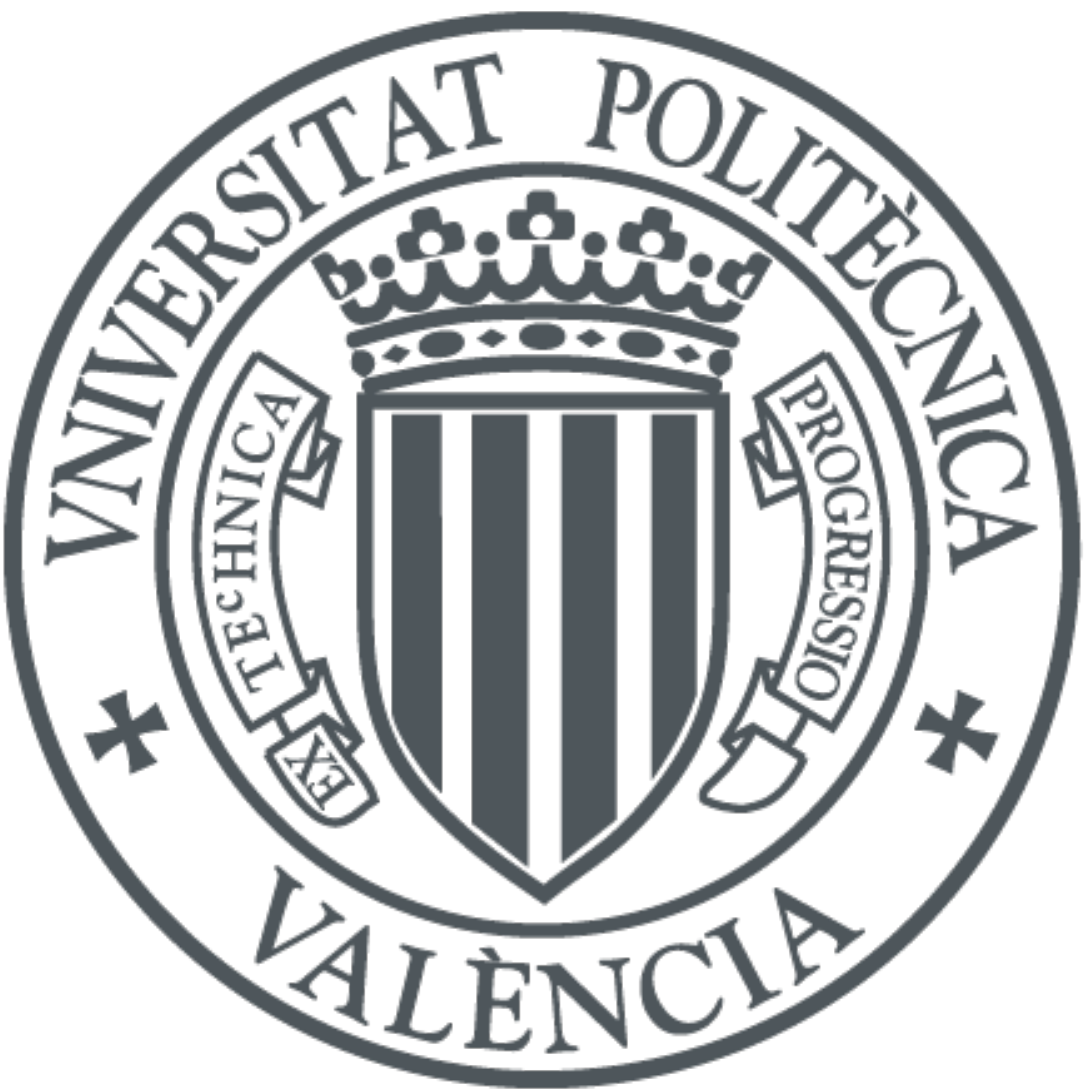

The final publication is available at

http://dx.doi.org/10.1016/S0021-9290(12)70294-4

Copyright Elsevier

Additional Information 


\title{
PROPAGATION OF ARTIFACT ERRORS ON KINEMATIC ANGLES. EFFECT ON EULER ANGLES
}

\author{
De Rosario, Helios (1), Page, A.(2), Mata, Vicente (3), Besa, Antonio (3), Moreno, \\ Rafael(1).
}

\section{Introduction}

Soft tissue artifacts (STA) are a major source of error in human movement analysis. STA measurements differs depending on subject characteristics, segment under analysis, task and markers location. Moreover, the way in which STA are described can introduce some additional variability. In particular, the use of Euler angles can amplify the effect of STA, in a similar way as the described by [1] for the case of accidental random errors propagation.

In this paper we propose explicit expressions to compute the propagation of STAs on the joint angles expressed as Euler angles.

\section{Methods}

From a kinematic point of view, the STA can be described as the relative motion of the marker cluster over the underlying bone. This motion is quantified by the displacement of the marker centroid, $\delta \mathbf{r}_{\mathrm{G}}$, as well as a small rotation, $\delta \boldsymbol{\theta}$. On the other hand, the motion of the underlying bone from a reference position implies a translation $\Delta \mathbf{R}_{\mathrm{G}}$ and a finite rotation. The angular displacement can be described by means of Euler angles, i.e. a sequence of rotations $\Phi_{1}, \Phi_{2}, \Phi_{3}$ around the axes $\mathbf{e}_{1}, \mathbf{e}_{2}, \mathbf{e}_{3}$, respectively. The rotation associated to the artefact propagates to the measured Euler angles as an error, $\mathrm{d} \Phi_{1}, \mathrm{~d} \Phi_{2}, \mathrm{~d} \Phi_{3}$. By assuming $\mathrm{d} \theta$ to be small ( $\mathrm{d} \theta<$ $\left.10^{\circ}\right)$, it is possible to prove that

$$
R \times \delta \boldsymbol{\theta}=d \Phi_{1} \mathbf{e}_{1}+d \Phi_{2} \mathbf{e}_{2}+d \Phi_{3} \mathbf{e}_{3}
$$

where $\mathrm{R}$ is the rotation matrix. Equation (1) represents a system of linear equations which coefficients depends of the selected Euler sequence. In the case of the sequence proposed for the lower limb, YX'Y', , [3] the solution of (1) is show in eq (2).

$$
\begin{aligned}
& d \Phi_{1}=\frac{s 3 d \theta_{x}-c 3 d \theta_{z}}{s 2} \\
& d \Phi_{2}=c 3 d \theta_{x}+s 3 d \theta_{z} \\
& d \Phi_{3}=d \theta_{y}+c 2 \frac{-s 3 d \theta_{x}+c 3 d \theta_{z}}{s 2}
\end{aligned}
$$

As Eq (2) shows, the propagation of STA to the Euler angles is non linear and present crossover effect. The propagation is very sensitive to $\Phi_{2}$ : for small values the error propagated to $\Phi_{1}$ and $\Phi_{3}$ is amplified.

\section{Experimental validation}

In order to validate the proposed model of error propagation an experiment was performed. We used a model of upper limb consisting of a rigid bar articulated en un rótula y rodeada de espuma deformable. Un conjunto de marcadores situados sobre la espuma simulan el movimiento con artefacto, mientras que otro conjunto unido a la barra permite medir el movimiento sin artefacto. La barra se movió a mano simulando diferente tipos de movimientos. The motion was reorded by a Kinescan-IBV. Kinematic análisis was performed as described in [3]

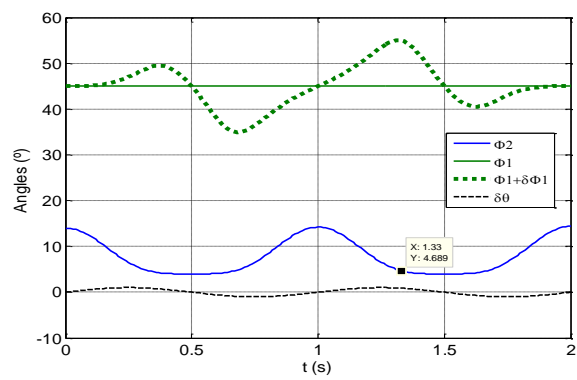

Figure 1

Los resultados muestran una buena correspondencia entre los errores angulares medidos y los estimados a partir de (2). En la figura 1 se muestra uno de los resultados del estudio que muestra la variabilidad en el error asociada al uso de ángulos deEuler, especialmente en valores pequeños de $\Phi_{2}$

\section{Conclusions}

The propagation of STA on the computed Euler angles is strongly nonlinear. The proposed equations show a crossover effect of STA components over the three Euler angles as well as the amplification effect associated to the singular configurations. Both facts introduce some avoidable variability in the description of STA.

\section{Acknowledgements}

This work has been funded by the Spanish Government and co-financed by EU FEDER funds (Grants DPI2009-13830-C02-01, DPI2009-13830C02-02 and IMPIVA IMIDIC/2010/84).

\section{References}

[1] Woltring et al, J Biomech, 37:1-10, 2006.

[2] Wuet al, J Biomech, 37:1-10, 2006.

[3] Page et al, J Mech Des.Biomech, 37:1-10, 2009. 